\title{
The use of endoscopy in fetal medicine
}

\author{
V. Beck • A. Pexsters • L. Gucciardo • T. van Mieghem • \\ I. Sandaite $\cdot$ S. Rusconi $\cdot$ Ph DeKoninck • \\ K. Srisupundit $\cdot$ K. O. Kagan $\cdot$ Jan Deprest
}

Received: 22 December 2009/Accepted: 25 January 2010/Published online: 9 March 2010

(C) Springer-Verlag 2010

\begin{abstract}
We aimed to review the state of affairs in the field of embryo-fetoscopy as well as its instrumental requirements. Today, endoscopic procedures of limited complexity are easily possible within the amniotic cavity. Embryoscopy is typically done for diagnostic purposes, such as the demonstration of external anomalies very early in pregnancy and/or obtaining embryonic tissues in recurrent miscarriages. Fetoscopy is the direct visualization of the amniotic cavity from the second trimester onwards. Its principal indications are complications of monochorionic twinning and severe congenital diaphragmatic hernia. There is level I evidence that fetoscopic laser surgery for twintwin-transfusion syndrome is superior over amniodrainage. Fetoscopic endoluminal tracheal occlusion is done for severe diaphragmatic hernia. Whether tracheal occlusion yields better outcomes than expectant management during pregnancies is currently being investigated in a randomized
\end{abstract}

V. Beck · A. Pexsters $\cdot$ L. Gucciardo $\cdot$ T. van Mieghem $\cdot$

S. Rusconi $\cdot$ P. DeKoninck $\cdot$ K. Srisupundit $\cdot$ J. Deprest $(\triangle)$

Division Woman and Child, Department Woman,

University Hospitals Leuven,

3000 Leuven, Belgium

e-mail: Jan.Deprest@uzleuven.be

V. Beck $\cdot$ L. Gucciardo · S. Rusconi $\cdot$ P. DeKoninck $\cdot$ J. Deprest Centre for Surgical Technologies, Faculty of Medicine,

Katholieke Universiteit Leuven,

Leuven, Belgium

I. Sandaite

Division of Medical Imaging, University Hospital Gasthuisberg,

Leuven, Belgium

\section{K. O. Kagan}

Department of Obstetrics and Gynaecology,

University Hospital Tuebingen,

Tuebingen, Germany trial. There are a number of less common procedures discussed as well. Overall, maternal risks of embryofetoscopy are minimal. The most frequent complication is rupture of the membranes and as a consequence preterm delivery. Fetal surgery seems safe and has, therefore, become a clinical reality. Although the stage of technical experimentation is over, most interventions remain investigational. Inclusion of patients into trials whenever possible should be encouraged, rather than building up casuistic experience.

\section{Keywords Fetal surgery · Fetoscopy · Embryoscopy ·} Prenatal diagnosis $\cdot$ Missed abortion

\section{Introduction}

Minimally invasive endoscopy became the gold standard for diagnosis as well as operative procedures in many fields of medicine during the last decades of the past century. Eventually, also the fetal patient does benefit today from this modality. Already in 1954, Bjorn Westin undertook the first attempts to visualize the human fetus with an endoscope [1]. Only in the 1970s embryoscopy and fetoscopy evolved as a more common diagnostic and therapeutic technique throughout ongoing pregnancy. Fetoscopy was performed to demonstrate external malformations such as neural tube defects $[2,3]$, to gain fetal liver and skin biopsies [4-6], or to obtain fetal blood in the diagnosis of, e.g., hemoglobinopathies [6, 7]. It also allowed for interventions, such as intravascular transfusion under direct visual control [8]. However, the invasiveness of the procedure, required skills, and a lack of suitable instruments lead to relatively high fetal loss rates. A report of the International Fetoscopy Group (1984) with pooled data of 
approximately 3,000 procedures in 24 programs reported an overall pregnancy loss rate prior to 28 weeks of $4 \%$ [9].

Diagnostic embryoscopy and fetoscopy were almost completely abandoned when high-resolution ultrasound became available [10]. Only the introduction of video endoscopy and miniaturized, light instruments into medicine in the 1990s paved the way for therapeutic endoscopic procedures in the pregnant uterine cavity [11, 12]. Prenatal screening at that point had evolved tremendously, with the vast majority of fetal anomalies detected still best being treated after birth. Yet, there are conditions that, without prenatal intervention, will lead to intrauterine fetal death (IUFD) or major organ damage. In these limited cases, fetal surgery offers the opportunity to tackle the malformation already in utero, either by definite therapy or by treating life-threatening effects of the distinct condition, delaying final therapy until after birth. Whereas open fetal surgery is associated with a high risk of preterm premature rupture of membranes (PPROM) and preterm delivery, fetoscopy seems a markedly less invasive therapeutic alternative $[13,14]$. Since, however, cases, in which a prenatal intervention is needed, are rare and medicolegal risks remain high, companies keep from investing in distinct fetoscopic instruments. Fortunately, in 1998, the European Union addressed this bottleneck by establishing the Eurofoetus program, a research and development project, which connected medical experts with the German manufacturer of endoscopes, Karl Storz. This initiative resulted in the development of numerous purpose-designed instruments and a boost for certain fetal procedures. First applications were in complicated monochorionic (MC) multiple pregnancies, but in the mean time, several conditions were defined that are accessible to endoscopic intervention [15]. A mere diagnostic intention is rare in nowadays fetoscopy, whereas it is the indication for embryoscopy. Conditions eligible for operative fetoscopy are listed in Table 1. For each of them, it is essential to accurately define diagnosis and prognosis, to rule out effective postnatal therapy, to gain experimental proof on safety and effectiveness of the planned intervention, and to perform within a trained multidisciplinary team as stated by the International Fetal Medicine and Surgery Society [17]. In this review, we provide an update on the current indications, the achievements for certain conditions as well as a short description of equipment used for distinct interventions in the field of embryo-fetoscopy.

\section{Embryo-fetoscopy}

Embryoscopy refers to the direct visualization of the products of conception prior to 12 weeks of gestation, either extra- or intra-amniotic. Conversely, fetoscopy is an endoscopic procedure performed on the pregnant uterus after 12 weeks of gestation. It allows access to the fetal side of the placenta, cord, membranes, and the fetus. Fetoscopy can now be done percutaneously under local or occasionally loco-regional anesthesia. Procedures remain, however, invasive, with as main maternal risk, bleeding, placental abruption, or the consequences of intra-amniotic infection. In clinical practice, these risks are minimal. The most important access-related complication is PPROM and, as a consequence, infection and preterm delivery. The

Table 1 Indications for fetoscopic surgery

\begin{tabular}{ll}
\hline Fetal surgery & Rationale for in utero therapy \\
CDH & Reversal of pulmonary hypoplasia and prevention of pulmonary hypertension \\
MMC & Covering of exposed spinal cord, prevention of hydrocephaly and hindbrain herniation \\
SCT & Reversal of cardiac failure and prevention of polyhydramnios \\
LUTO & Prevention of renal failure and pulmonary hypoplasia \\
Surgery on the placenta, cord, or membranes & Rationale for in utero therapy \\
Complicated MC pregnancies & \\
TTTS & Functional bichorionization or arrest of feto-fetal transfusion and its consequences \\
TRAP and other discordant anomalies & In some conditions (TTTS/TRAP), reversal of cardiac failure and polyhydramnios \\
TAPS & In some conditions, selective feticide is a goal in itself \\
sIUGR & Prevention of deformities and functional loss \\
ABS & Prevention of cardiac failure, hydrops fetoplacentalis, and polyhydramnios \\
Chorioangioma &
\end{tabular}

Adapted from Deprest [16]

$C D H$ congenital diaphragmatic hernia, MMC myelomeningocoele, SCT sacrococcygeal teratoma, LUTO lower urinary tract obstruction, $M C$ monochorionic, ABS amniotic band syndrome, sIUGR selective intrauterine growth restriction, TTTS twin-twin-transfusion syndrome, TAPS twin-anemia-polycythemia sequence 
estimated occurrence rates of (P)PROM according to the procedures performed are displayed in Table 2. Procedurespecific, as well as risks related to the distinct fetal condition, may add to these generic risks. Overall, these potential risks must be outweighed against the claimed benefit of the procedure.

\section{Instruments}

Current embryo-fetoscopes come with a working length of 20 $30 \mathrm{~cm}$ and a diameter of 1.0-3.8 $\mathrm{mm}$. They are designed such that they are a compromise between the smallest diameter technically possible that still allows sufficient image quality. In some models, the standard eyepiece has been deported to reduce weight and allow for an ergonomic manipulation. Roughly spoken, two types are available, i.e., (a) rod lens endoscopes where the image itself is focused by a Hopkins rod lens system; (b) fiber endoscopes which use optical fibers for both light and image transmission. This way, they can be made in smaller diameters with a sufficient length and image quality. Fetoscopes are typically protected by a sheath, which may have additional operative channels for instruments or infusion.
In analogy to laparoscopy, access needs to be gained by a cannula (or port). This cannula enables the surgeon to change instruments during the intervention and, in theory, reduces membrane friction, however, at the expense of a larger diameter. The port can be inserted into the amniotic cavity using a stabbing trocar or over a guide wire and dilator (Seldinger technique) [29, 38-40]. Alternatively, the fetoscope sheath can be inserted directly, using a pyramidal obturator within. The amniotic cavity is spontaneously distended by the amniotic fluid. When that does not create enough working space, additional infusion or, in case of unclear fluid, substitution or exchange can be done. We use warmed, isotonic Hartmann solution, which has been proven to be safe in experimental and clinical conditions [41, 42]. Gas distension $\left(\mathrm{CO}_{2}, \mathrm{~N}_{2} \mathrm{O}\right)$ may permit a clearer view, even in the presence of bleeding, yet interferes with the use of ultrasound and some fear fetal side effects [43-46]. The camera system and light sources are no different from other endoscopic operations, though the light cables are smaller in diameter.

Most fetoscopic procedures are done under local anesthesia. An anesthetic is injected down to the myometrium at the anticipated cannula tract. This site is deter-

Table 2 Reported risks for PROM following fetoscopic procedures in selected case series

\begin{tabular}{|c|c|c|c|c|}
\hline $\begin{array}{l}\text { Procedure } \\
\text { (for) }\end{array}$ & $\begin{array}{l}\text { Number of } \\
\text { cases }\end{array}$ & $\begin{array}{l}\text { Risk PROM } \\
\text { (time point at assessment) }\end{array}$ & Diameter instrument & Reference \\
\hline \multirow[t]{2}{*}{ MMC } & 3 & $67 \%$ & $3.8 \mathrm{~mm}$ & Kohl [18] \\
\hline & 4 & $33 \%$ & 3 ports, largest $5.0 \mathrm{~mm}$ & Bruner [19] \\
\hline \multirow[t]{2}{*}{ LUTO } & 10 & $17 \%$ & $1.3 \mathrm{~mm}$ & Welsh [20] \\
\hline & 13 & $13 \%$ & $\leq 2.6 \mathrm{~mm}$ & Quintero [21] \\
\hline \multirow[t]{3}{*}{ ABS } & 2 & $100 \%$ & $3.3 \mathrm{~mm}$ & Soldado [22] \\
\hline & 2 & $100 \%$ & $4.0 \mathrm{~mm}$ & Keswani [23] \\
\hline & 2 & $50 \%$ & $2.7 \mathrm{~mm}$ & Quintero [24] \\
\hline \multirow[t]{6}{*}{ Placental laser } & 4 (TTTS) & $75 \%$ & $5.0 \mathrm{~mm}$ & Kohl (secondary laser) [25] \\
\hline & 6 (TTTS) & $33 \%$ & $3.3 \mathrm{~mm}$ & Van Schoubroeck (triplets only) [26] \\
\hline & 175 (TTTS) & $\begin{array}{c}28 \%(<34 \text { weeks }) \\
7 \%(<1 \text { week })\end{array}$ & $3.3 \mathrm{~mm}$ & Yamamoto and Ville [27] \\
\hline & 20 (TTTS) & $5 \%(<28$ weeks $)$ & $3.3 \mathrm{~mm}$ & Crombleholme [28] \\
\hline & 24 (TTTS) & $4 \%$ & $4.0 \mathrm{~mm}$ & Chang [29] \\
\hline & 6 (TRAP) & $0 \%(<3$ weeks $)$ & $2.0 \mathrm{~mm}$ & Quintero [30] \\
\hline \multirow[t]{5}{*}{$\mathrm{CO}$} & 80 & $38 \%$ & 2.3 or $3.3 \mathrm{~mm}$ & Lewi (bipolar/laser) [31] \\
\hline & 4 & $25 \%$ & $2.7 \mathrm{~mm}$ & Ville (laser) [32] \\
\hline & 39 & $20 \%(<3$ weeks $)$ & $3.5 \mathrm{~mm}$ & Quintero (ligation \pm transection/laser) $[30$ \\
\hline & 25 & $16 \%(<3$ weeks $)$ & $3.5 \mathrm{~mm}(1$ or 2 ports $)$ & Nakata (ligation/laser) [33] \\
\hline & 12 & $8 \%$ & $3.0 \mathrm{~mm}$ & Young (bipolar) [34] \\
\hline \multirow[t]{2}{*}{ FETO } & 11 & $100 \%$ & $5.0 \mathrm{~mm}(1$ or 3 ports $)$ & Harrison [35] \\
\hline & 210 & $\begin{array}{l}47 \% \\
17 \%(<3 \text { weeks })\end{array}$ & $3.0 \mathrm{~mm}$ & Jani [36] \\
\hline
\end{tabular}

Rupture rates (\%) are those reported $\geq 37$ weeks or at the time point specified (adapted from Deprest [37])

$C O$ cord occlusion, FETO fetoscopic endoluminal tracheal occlusion 
mined by the purpose of the procedure but should ideally be in an area devoid of placenta. For placental surgery, no fetal anesthesia is needed. For interventions on the fetus, both fetal analgesia and immobilization are required. Most use injection of fentanyl and pancuronium (or an analog), which are either injected intramuscular or intravenous in the appropriate dose, based on fetal weight estimation. Historically, interventions have been done under general anesthesia, but today, this is rarely necessary, except for open surgical procedures. In that case, no additional fetal analgesia is usually required [47].

\section{Embryoscopy}

The embryo can be directly visualized either by transabdominal or transcervical access. Thin-gauge embryoscopy was developed in the mid-1990s [11]. It involves the ultrasound-guided transabdominal introduction of a single or double lumen small diameter sheath or needle. This can be done under local anesthesia. Once inside, the trocar(s) is removed to allow a thin fiber-endoscope. Typical indications are the visualization of external anomalies which might not be visible or uncertain using ultrasound, in selected families at risk for certain genetic conditions or malformations [48]. The insertion should be well planned and directed such that the area of interest can be visualized, because only a partial view of the embryo can be obtained. This pertains particularly when visualizing for instance facial clefts or abdominal wall defects (Fig. 1). Once inside an ongoing pregnancy, only gentle movements can be performed with the tip of the instrument or limited infusion. Intra-amniotic bleeding may occur in $10-15 \%$ of cases, which will limit further visualization so that the procedure may be aborted. Increasing resolution of modern ultrasound equipment has largely obviated the need of this technique, especially for pregnancies beyond 12 weeks gestational age (GA). However, at 8 weeks, facial or limb deformities may not always be easily detectable by ultrasound, even by using high-definition transvaginal probes.

Recently, transcervical embryoscopy has been revived in the evaluation of missed abortions before 12 weeks, in particular in recurrent miscarriages or fertility treatment programs [49]. In the latter, failing pregnancies might be biochemically identified very early in their course and as such could be assessed electively. In that case, endoscopic equipment is introduced through the cervix, and the procedure may be completed with evacuation of the products of conception. For this, larger equipment is often used, consisting of $0^{\circ}$ or $30^{\circ}$ hysteroscope, housed within a double flow sheath allowing for exchange of irrigation fluid (at body temperature and a pressure $40-120 \mathrm{mmHg}$ ) [50, 51] and insertion of instruments (Bettocchi $3.6 \mathrm{~mm} 5 \mathrm{Ch}$ operating sheath with $30^{\circ}$ scope of $2 \mathrm{~mm}$ diameter, Karl Storz GmbH, Tuttlingen, Germany). The operator first localizes the gestational sac and surgically opens the chorionic membrane. At that time, the embryo can already be seen through the amnion. Further opening of the amniotic membrane with micro-scissors allows a closer look at the different fetal elements and from different sides.

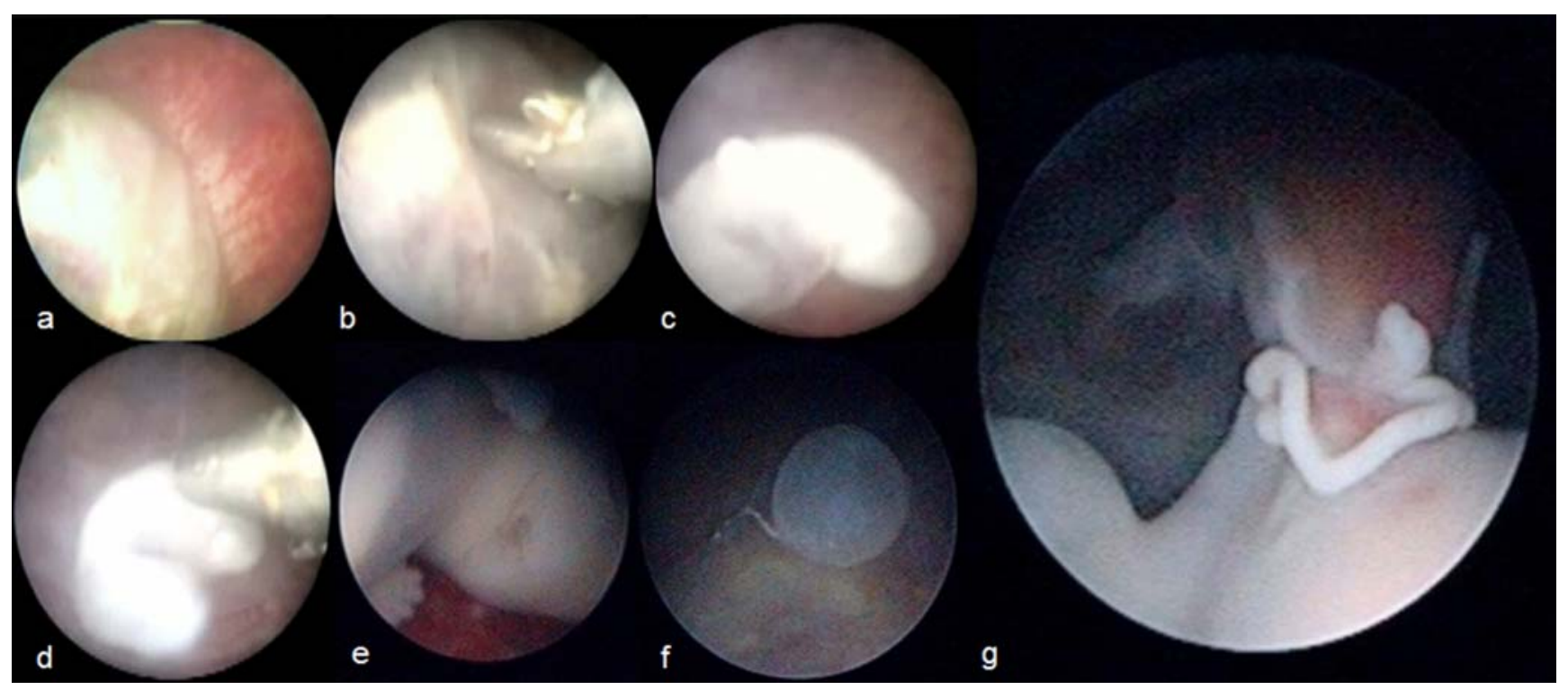

Fig. 1 Different steps in embryoscopy. Hysteroscopic view of $a$ the gestational sac; $b$ surgical opening of the chorionic membrane; $c$ transamniotic membrane view of the embryo; $d$ forceps retrieval of the embryo; $e$ intra-amniotic view of an embryo with a cleft lip. The embryo in (e) had translocation dup(4q32.3-qter), dup(10pter-q11.22), $\mathrm{XY}$; $f$ view of the yolk sac; $g$ Gastroschisis in a trisomy 16 embryo (C) UZ Leuven) 
Also, the yolk sac and umbilical cord are inspected. Normal or anomalous evolution is usually described and dated in function of the crown-rump length as measured on ultrasound or described in the Carnegie stages [52]. After that, direct sampling of chorionic villi is possible, as well as directed embryonic biopsies. Prior to 7 weeks, the embryo can usually be removed in toto. One can use ultrasound guidance, which in our experience facilitates localization of the gestational sac and the structures inside. In summary, next to external or phenotypic description, embryoscopy allows the prelevation of pure embryonic material, without maternal contamination, for further genetic testing. The procedure can be part of the formal evacuation of the products of conception and would lengthen that procedure only by $10 \mathrm{~min}$. Also, the procedure-related complications are similar, i.e., bleeding, infection, and perforation.

Paschopoulos et al. leave the amnion intact and report on 42 patients with first trimester miscarriage [53]. Ferro et al. work intra-amniotically and published data on 68 patients presenting with missed abortion in an IVF program. Compared to material obtained from curettage, cytogenetic analysis of embryoscopic prelevations was more informative in $22 \%$ of cases [50]. Philipp et al. reported abnormal standard karyotyping with G-banding in as many as $75 \%$ of 233 missed abortions. Eighteen percent had a variety of abnormal phenotypic features, despite a normal karyotype. In $7 \%$, no phenotypical or cytogenetic abnormalities could be found [51]. The same group described the typical phenotype of triploidy with severe cranio-facial malformations, retarded limb development, delayed retinal pigment development, and neural tube defects [54]. Monosomy 45X is associated with microcephaly, encephalocoele, and limb retardation [55]. Obviously, those defects would not show up on curettage specimens nor would they be typically seen on high-definition ultrasound.

\section{Twin-twin-transfusion syndrome}

MC twins account for $20 \%$ of twin pregnancies. In all of them, placental vascular anastomoses are found and in about $10 \%$ twin-twin-transfusion syndrome (TTTS) arises as a consequence [56]. Specific angioarchitectural patterns cause a net blood flow from one fetus (donor) to the other (recipient). As a consequence, the donor twin is hypovolemic and has oligouria leading to oligohydramnios, whereas the recipient twin shows hypervolemia, leading to polyuric polyhydramnios. The diagnostic criteria for TTTS used in Europe are a deepest vertical pocket (DVP) for the donor of $<2 \mathrm{~cm}$, while in the recipient, the DVP should measure $\geq 8 \mathrm{~cm}$ before 20 weeks and $\geq 10 \mathrm{~cm}$ beyond 20 weeks of gestation. In the USA, a cutoff of $8 \mathrm{~cm}$ at all timepoints in gestation is used. The disease is staged by ultrasound features, depending on the presence (stage I) or absence of bladder filling in the donor (stage II), Doppler abnormalities in any fetus (stage III), or hydrops (stage IV) [57]. Whereas stage relates to outcome, it has no proven consequences towards management [58]. Table 3 illustrates currently known stage-related outcome in TTTS after laser surgery. TTTS typically occurs between 16 and 26 weeks of gestation. The natural history of this disease is disastrous, with a pregnancy loss rate of $80 \%$ or more [59]. Until the late 1990s, the standard of care was serial amnioreduction, reducing the loss rate to around 50\% [60]. Drainage does improve placental perfusion [61] but mainly reduces the risk of preterm delivery.

A more causative approach is fetoscopic inspection of the placenta and laser coagulation of chorionic plate anastomoses (Fig. 2). For that purpose, the ideal entry is at a $90^{\circ}$ angle towards the anticipated vascular equator. In reality, the placenta and the two cords are the landmarks, and one enters well away from the anticipated membrane insertion to avoid septostomy. Most use a 400 or $600 \mu \mathrm{m}$ bare laser fiber connected to a neodymium/yttrium-aluminum-garnet $(\mathrm{Nd}$ : YAG, wavelength $1,064 \mathrm{~nm}$, reported power requirements 50-100 W, e.g., Medilas Fibertom 8100, Dornier MedTech, Wesling, Germany) or a $940 \mathrm{~nm}$ diode (20-60 W, e.g., Medilas D Multibeam Dornier MedTech) laser source [60]. With a non-touch technique, all visible anastomoses are coagulated over a 1 to $2 \mathrm{~cm}$ section until visual cessation of flow. The goal is to bichorionize the placenta. This not only arrests the TTTS but also prevents exsanguination of one twin into the other after single IUFD. This might be a consequence of recurrent TTTS (10-14\%) through remaining anastomoses

Table 3 Stage-related outcome after laser therapy in TTTS

\begin{tabular}{lcccr}
\hline & 0 survivors & 1 survivor & 2 survivors & at least 1 survivor \\
\hline Stage I $(n=29)$ & $6.9(0.8-22.8)(2 / 29)$ & $17.2(5.9-35.8)(5 / 29)$ & $75.9(56.5-89.7)(22 / 29)$ & $93.1(77.2-99.2)(27 / 29)$ \\
Stage II $(n=81)$ & $17.3(9.8-27.3)(14 / 81)$ & $22.2(13.7-32.8)(18 / 81)$ & $60.5(49.0-71.2)(49 / 81)$ & $82.7(72.7-90.2)(67 / 81)$ \\
Stage III $(n=80)$ & $17.5(9.9-27.6)(14 / 80)$ & $28.7(19.2-40.0)(23 / 80)$ & $53.8(42.2-65.0)(43 / 80)$ & $82.5(72.4-90.1)(66 / 80)$ \\
Stage IV $(n=10)$ & $30(6.7-65.2)(3 / 10)$ & $20(2.5-55.6)(2 / 10)$ & $50(18.7-81.3)(5 / 10)$ & $70(34.8-93.3)(7 / 10)$ \\
\hline
\end{tabular}

Data is given as $\%$ of pregnancies ( $95 \%$ confidence interval) and (number of pregnancies with given number of survivors/ total number of pregnancies at this Quintero stage); adapted from Huber [58] 
[62-64] (which happens more than anticipated [65]). For that reason, the patient needs to be screened for recurring twinoligo-polyhydramnios sequence or elevation of the peak systolic velocity in the middle cerebral artery, pointing to anemia. IUFD is not uncommon, and this may affect both the donor as well as the recipient. In the donor, fetal demise is related to preoperative umbilical artery (UA) Doppler abnormalities, whereas in the recipient postoperative UA Doppler abnormalities increase the risk for IUFD [66].

The procedure is completed by amnioreduction to normal levels. Complications are peritoneal irritation by amniotic fluid leakage through the uterine entry point, iatrogenic PPROM (7\% within 1 week, $28 \%$ before 34 weeks), placental abruption (1\%), as well as infection and hemorrhage in rare cases $[27,60]$. An earlier drainage or stained liquid may hamper visualization, as well as an unfavorable placental location [25, 67]. For patients with anterior placentas, special techniques and instruments have been designed. These include a deflecting mechanism built in the sheath [68], side firing laser fibers through an additional insert [69], and even a laparoscopic-assisted posterior uterine access [70]. So far, none of these techniques has been proven superior, and for that reason, we personally remain mostly with the use of curved scopes of the same diameter and lateral trocar insertion [71]. Other groups achieve similar results by the consequent use of other techniques [68].

The superiority of laser over amniodrainage was proven in the Eurofoetus randomized trial [60]. Laser treatment resulted in a later delivery (33.3 versus 29 weeks), a better survival rate at 6 months of age (at least one survivor in $76 \%$ compared to $51 \%$ ), and less neurological impairment (intraventricular hemorrhage grades III or IV, $1 \%$ versus $6 \%$; cystic periventricular leukomalacia, $6 \%$ versus $14 \%$; infants alive without major complications at 6 months, 52\% versus $31 \%$ ). Later meta-analyses [72, 73] and a Cochrane review [74] confirmed this including other series; therefore, laser is the current standard of care.

A lower neurologic morbidity in survivors has been confirmed in other studies as well, but the studies giving these results were not designed with carefully selected controls. In a more recent follow-up study on infants born after laser surgery, $18 \%$ showed neurological impairment at age 2 years (cerebral palsy $6 \%$, severe mental delay $7 \%$, severe psychomotor delay $12 \%$, bilateral blindness $1 \%$, bilateral deafness $1 \%$ ). Risk factors for neurodevelopmental impairment were an advanced GA at laser therapy, a low GA at birth, a low birth weight, and a more advanced stage at laser. Post-laser neurologic sequel do not differ in donor or recipient twin [75]. However, some of the lesions may not be related to TTTS, as we recently showed a background neurologic impairment rate of $7 \%$ in apparently normal MC twins [76]. As this is probably the most feared complication of TTTS, we routinely perform follow-up ultrasound as well as a fetal MRI around 30-32 weeks in pregnancy to rule out this condition as much as possible.

Another cause of morbidity are cardiac complications, which may be as high as $10 \%$ in recipients, who are prone to right ventricular outflow tract obstruction. On the other hand, the majority of recipients, who all have a vast cardiac overload, recover already in utero from cardiac dysfunction $[77,78]$.

\section{Other complications of monochorionic pregnancies}

MC twins are more prone to structural anomalies, more than $80 \%$ being discordant. They can even be discordant

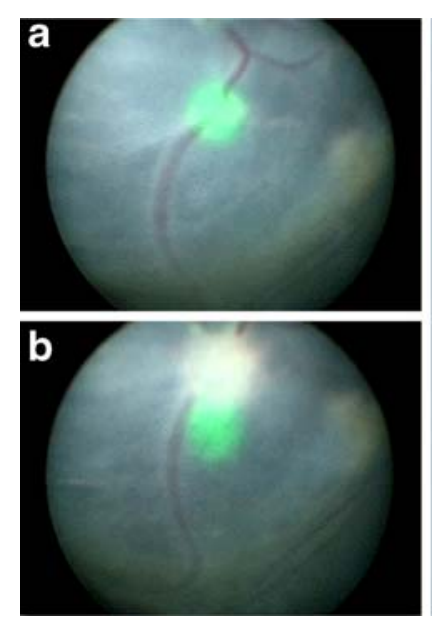

Fig. 2 Laser coagulation of chorionic plate anastomoses. Fetoscopic view of placental vascular anastomoses before (a) and after (b) laser coagulation. c Equipment for fetoscopic laser surgery: $3 \mathrm{~mm}$ curved double lumen sheath to be used with $2 \mathrm{~mm}$ fiber fetoscope with

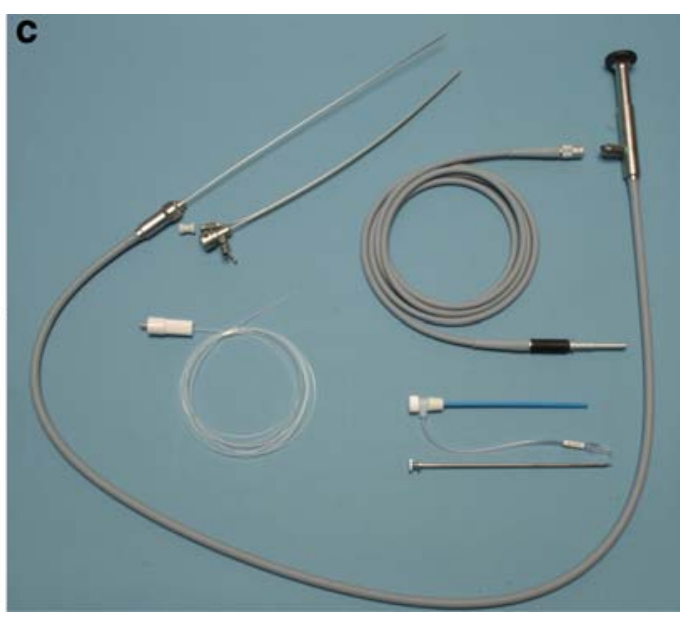

deported eyepiece and laser fiber (Dornier MedTech, Wesling, Germany); $3.3 \mathrm{~mm}$ cannula (Cook Medical Inc., Bloomington, IN, USA) and trocar; light cable. If not specified otherwise, instruments are from Karl Storz, Tuttlingen, Germany (C) UZ Leuven) 
for aneuploidy [79]. Parents may decide not to deliver such baby alive, and selective feticide avoids termination of the entire pregnancy. Another anomaly is twin-reversedarterial-perfusion sequence (TRAP or acardiac fetus). Functionally spoken, the anomalous is perfused by the normal "pump" twin, which risks to develop congestive heart failure and hydrops in $>50 \%$ [80]. Fetal death puts the healthy one at risk, due to feto-fetal hemorrhage over the anastomoses.

Another not infrequent clinical scenario is that of selective intrauterine growth restriction (sIUGR), e.g., defined by a sonographic estimated fetal weight $<10$ th percentile in the growth restricted fetus. However, different definitions are used and are discussed in detail by Russel et al. [81]. sIUGR complicates around $7-15 \%$ of MC twins, and these pregnancies are extremely difficult to manage. There is no agreement what the criteria are to determine when a growth restricted fetus is at an extremely high risk for IUFD, but in that event, the MC status puts the other fetus at risk for fetal death or (neurological) morbidity [8284] due to the anastomoses [85]. For that reason, some have proposed to actively manage these pregnancies. In analogy to TTTS, laser bichorionization can be done, but technically, the procedure is more difficult because of the absent polyhydramnios, hence, more scalloped placenta. Also, the angioarchitecture is different. Another intervention that can be done in such circumstances is selective feticide to protect the other fetus $[81,86]$. This concept is supported by a recent retrospective study on $135 \mathrm{MC}$ pregnancies after single (spontanous, post cord occlusion, or laser bichorionization) IUFD. Brain injuries that were picked up by MRI were significantly less in the survivors of cord occlusion or laser intervention (3\%) compared to spontaneous co-twin loss (22\%) [87].

Selective feticide in MC twins needs to be done with alternative techniques to potassium chloride injections because both fetal circulations are functionally one unit. This is achieved by surgical obliteration of both the arterial and venous flow, preferentially nearly simultaneous. Several techniques are available today. The largest experience is by ultrasound or sono-endoscopic guided bipolar cord coagulation, using forcepses of 2.4 or $3.0 \mathrm{~mm}$, according to the cord size. Cord occlusion has a $78-84 \%$ survival rate $[31,88]$. Pre- and perinatal losses of the healthy twin are mainly due to cord entanglement because of iatrogenic rupture of the intertwin membrane or consequences of early PPROM also responsible for $7 \%$ developmental problems in survivors. An effect of operator experience was demonstrated, showing decrease in PPROM and morbidity after 40 procedures [31]. Alternative energy sources such as laser, monopolar, or radiofrequency energy may be used through 14-18 G needles [89-91]. They work effectively in TRAP where low-flow conditions are present and all energy modalities show comparable outcomes [30, 92]. A special scenario is found in discordant monoamniotic pregnancies. Here, cord occlusion should be combined with subsequent cord transsection [39].

\section{Congenital diaphragmatic hernia}

Congenital diaphragmatic hernia $(\mathrm{CDH})$ is a surgically correctable defect with an incidence of 1/5,000 newborns. Along with the diaphragmatic lesion, babies have variable degrees of lung hypoplasia leading to ventilatory insufficiency, and in survivors, pulmonary hypertension. These are the major causes of postnatal death, still occurring in up to $30-40 \%$ of cases where the condition is isolated [93]. When there are associated anomalies, prognosis is worse. Lethal pulmonary hypoplasia can be diagnosed prior to birth, e.g., by measurement of the so-called lung-to-head ratio (LHR) [94]. This is a two-dimensional assessment of the contralateral lung, expressed as a ratio of head circumference. To discount for the different growth pattern of the lung and the head during gestation, the index or observed LHR is proportionated to what can be expected in a normal fetus of the same GA (observed/expected (O/E) LHR) [95]. Also, liver position is an independent predictor of outcome [93]. Fetuses with liver herniation and an O/E LHR $<25 \%$ have a predicted survival chance of less than $20 \%$ [95]. In these severe cases, prenatal intervention can be offered, which aims to reverse the pulmonary hypoplasia by stimulating lung growth. This can be achieved by prenatal tracheal occlusion, preventing egress of lung fluid, hence, inducing tissue stretch. Today, fetoscopic endoluminal tracheal occlusion (FETO) can be done by percutaneous access (Fig. 3). A balloon is positioned under visualization with a $3.3-\mathrm{mm}$ scope in the trachea, typically between 26 and 28 weeks (canalicular phase of lung development), and ideally, it is removed at 34 weeks (saccular-alveolar phase) fetoscopically or via ultrasound-guided needle puncture. This "plug-unplug sequence" stimulates lung maturation and allows vaginal delivery outside of the FETO center [96, 97]. The EXIT (ex-utero intrapartum treatment) procedure is an intrapartum alternative in case of preterm birth. Recently, the experience in 210 cases was reported on by the FETO consortium. FETO was performed at a median gestation of 27.1 weeks and PPROM prior to 37 weeks occurred in $47.1 \%$ of cases at a median of 30 days after FETO. A more informative number is that PPROM occurred within 3 weeks in $16.7 \%$ of cases. Although still clinically highly relevant, this is much less than in the earlier experience at San Francisco [35]. Delivery took place at a median of 35.3 weeks. Again, it was before 34 weeks in $30.9 \%$ of cases. In $204(97.1 \%)$ cases, the babies were live born and $98(48.0 \%)$ were discharged from 

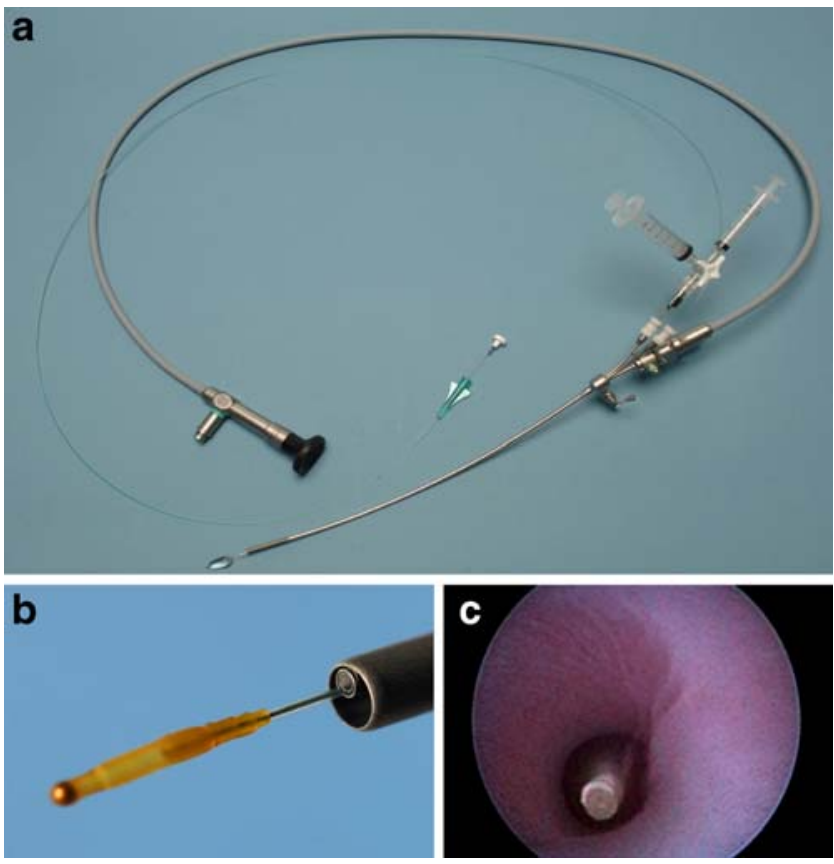

Fig. 3 Fetoscopic endoluminal tracheal occlusion. a $3 \mathrm{~mm}$ triple lumen curved sheath loaded with $1.3 \mathrm{~mm}$ fiber fetoscope with deported eyepiece and balloon catheter (e.g., BALT, Montmorency, France) carrying an inflated balloon (e.g., GVB 16, Cathnet Science, Paris, France) at the tip. The third channel is prepared for fluid sampling. b Detail of same sheath, fetoscope, and balloon catheter now with deflated balloon. c Fetoscopic view of inflated balloon after detachment from the catheter in the fetal trachea (if not specified otherwise, instruments from Karl Storz, Tuttlingen, Germany) (C) UZ Leuven)

the hospital alive. On the basis of the relation between survival and observed/expected LHR in expectantly managed fetuses with $\mathrm{CDH}$, as reported in the antenatal $\mathrm{CDH}$ registry, we estimated that in fetuses with left $\mathrm{CDH}$ treated with FETO, the survival rate increased from $24.1 \%$ to $49.1 \%$, and in right $\mathrm{CDH}$, survival increased from $0 \%$ to $35.3 \%(p<0.001)$. Median operation time was $10 \mathrm{~min}$ and depended on surgeon experience. It also predicted the occurrence of PPROM. The strongest predictors of outcome were $\mathrm{O} / \mathrm{E}$ LHR prior to the procedure, PPROM, and GA at delivery [36].

A later occlusion is proposed in moderate $\mathrm{CDH}(25 \%<$ $\mathrm{O} / \mathrm{E}$ LHR $<45 \%$ ), where a lesser lung response might still allow survival, and where the intervention targets at a reduction of the oxygen need in the postnatal period [98100]. Whether FETO is better than expectant management during pregnancy is currently being investigated in the TOTAL trial. Meanwhile, FETO has also been applied to fetuses at risk for severe lung hypoplasia due to persistent oligohydramnios [101]. This more recent indication will require validation of selection criteria for lethal hypoplasia due to PPROM.

\section{Myelomeningocoele}

In myelomeningocoele (MMC), the spinal cord protrudes through a defect in the bone and usually through the skin as well. The condition also has remote effects on fetal development, such as cerebellar herniation and hydrocephalus due to abnormal dynamics in cerebrospinal fluid production. The subsequent handicaps associated with MMC include lower limb paralysis, sensory loss as well as bladder, bowel, and sexual dysfunction, but there may be cognitive impairment as well. The severity of MMC is dependent on the level and extent of the spinal defect. This is why most children with MMC have a normal intelligence quotient, walking abilities, and social continence. Ventriculo-peritoneal shunting is often required, a known additional risk factor for cognitive impairment [102-104].

Experimental and clinical data suggest that neurological impairment progresses throughout pregnancy. Hence, fetal therapy might favor long-term outcome by preventing exposure to the amniotic fluid as well as cerebrospinal fluid leakage. This should reduce the chance for hydrocephalus, hindbrain herniation, and result in lower shunt requirement after birth [40, 105]. Another theoretical advantage of fetal surgery is that the repair would be less prone to scarring, avoiding the so-called tethered cord syndrome [106], although adhesions between spinal cord and skin after fetal surgery have been reported [107-109].

The US-based Management of MMC study (MOMS), which started in 2003 in three centers, will determine whether prenatal (19-25 weeks) yields better results than postnatal closure. Recruitment is still ongoing, and results are eagerly awaited. In this trial, the operation is carried out by open access, after an initial pilot study using an endoscopic approach with poor results $[19,43]$. The potential of robotic surgery [110] or alternative "sealing" of the defect with a patch through fetoscopy is currently being explored. The first fetoscopic applications of a patch failed as one out of three babies all born $\leq 30$ weeks died from prematurity, and the two remaining ones required postnatal shunting, therefore, not meeting trial goals [18]. In a more recent attempt, the same group tried a fetoscopic double patch (first patch is absorbable and covered by a non-absorbable second one) approach in two more infants. Although GA at delivery was 33 weeks now, and reversal of hindbrain herniation was seen in both cases, one child still struggled with prematurity effects, and the other one required shunting [107].

\section{Sacrococcygeal teratoma}

Sacrococcygeal teratoma (SCT) is the most frequent tumor in neonates with an estimated prevalence of one in 40,000 [111]. It is easily diagnosed before birth with ultrasound, 
Doppler, and MRI providing detailed information about location, size, and functional impact. Long-term outcome after standard therapy including postnatal tumor removal and follow-up for malignancy is usually excellent. Yet, a subgroup of SCT are large, fast-growing, and highly vascularized tumors, which set the fetus at risk for anemia and cardiac failure due to arterial-venous fistulas. Fetal hydrops and placentomegaly are accepted indicators for fetal intervention [112-115]. Causative approaches comprise open fetal tumor resection or debulking, which was published in eight cases with a mean GA of 28 weeks (range 26-29) and four survivors [116-118]. There is casuistic experience with less-invasive interventions such as thermocoagulation, radiofrequency ablation, embolization, and laser surgery [115, 119-121]. The London group treated four hydropic fetuses with laser; only one survived after preterm birth at 32 weeks, two died in utero, and one as a neonate after preterm delivery at 28 weeks [115]. In an earlier case report, Hecher et al. [122] describe successful partial SCT ablation via fetoscopic laser at 20 weeks of gestation. However, this fetus was not hydropic, and decision for fetal intervention was made based on polyhydramnios. The concurrent fetal anemia may need to be addressed as well, perhaps prior to surgery.

\section{Uncommon fetoscopic interventions}

Placental chorioangiomas are benign tumors that cause fetal heart failure due to a vascular steal mechanism. When treatment cannot wait until birth (e.g., in case of fetal hydrops), fetoscopic devascularization can be done, using an equipment that is the same as for laser therapy. Alternatives are embolization of the vascular plexus, either by alcohol or coils. The condition is too rare to reasonably assess as to which is the best technique [123-127].

Amniotic bands may lead to progressive constrictive lesions and amputate fetal body parts. The first one to describe a fetoscopic-guided lysis of such bands was Quintero [24], and several case reports were published since. Instrumentation consists of a $1.3-\mathrm{mm}$ fetoscope, which is inserted into a special sheath ending up in scissors. This allows fetoscopic control of the section of the bands. Alternatively, laser can be used, but that can cause collateral damage [22, 23]. It might be very difficult to section the bands entirely as they get entrapped within edematous surrounding structures.

Endoscopy is also used in the exploration of urinary tract lesions. Particularly male fetuses can develop complete lower urinary tract obstruction. This leads to two problems: one is secondary renal failure but the subsequent oligohydramnios-induced pulmonary hypoplasia is lifethreatening. So far, the standard prenatal intervention that salvages the lungs, and in well-selected cases also kidney function, is urinary diversion. Vesicoamniotic shunting is a palliative intervention that allows further repair after birth. They can also dislodge or become unfunctional in $20-40 \%$ of cases, requiring reinsertion [128-131]. The material used for fetal shunting is of comparable diameter to that of fetoscopic instruments. This means that with a similar access port, one can try to also assess the lower urinary tract by inserting an endoscope and perform fetal cystoscopy. It was Quintero who should be credited for performing the first percutaneous fetal urethral valve ablation [132, 133], i.e., a causative intervention. Alternatively, hydro- or laser ablation of urethral valves or antegrade catheterization can be done $[20,134]$. However, so far, the reported successful experience remains casuistic, and also, the role of diagnostic fetal cystoscopy remains to be determined.

\section{Conclusion}

Fetoscopic surgery has become a clinical reality in selected large fetal medicine units. The equipment is nothing but purpose-designed miniaturized variants of conventional endoscopic hardware. A number of indications for minimally invasive surgery within the womb have been established, and several more are under investigation. Fetoscopic surgery has proven its superiority in laser surgery of the placenta, and at present, its place in the prenatal treatment of $\mathrm{CDH}$ is being investigated within a European trial. The less invasive nature has made fetoscopic surgery more acceptable for parents and clinicians. However, a few more complex fetal surgical interventions remain impossible with current equipment. Fetoscopy is an invasive technique, with inherent consequences. Whereas PPROM, and subsequent preterm delivery, seems less frequent than with open surgery, it still is limiting current applications. Its increasing application and mediagenicity has triggered the interest to embark on fetal surgical therapy although the complexity as well as the overall rare indications are a limitation to sufficient experience on an individual basis. Therefore, these procedures may probably only be done properly when sufficient volume is available. Also, further advance in this field will only be possible by inclusion of patients into trials whenever possible, rather than building up casuistic experience.

Acknowledgment The European Commission supports fetoscopy in Europe through different funding mechanisms (EuroSTEC, 6th Framework, LSHC-CT-2006-037409; Marie Curie Early Stage Research Training MEST CT2005 019707), and provided the doctoral grants for VB, LG. The Flemish Regional Government (IWT/ 070715) supports our local fetoscopy program for Congenital Diaphragmatic Hernia and the stipend of PDK. JDP is a "clinical researcher" for the Fonds voor Wetenschappelijk Onderzoek Vlaanderen (1.8.012.07. N.02). AP and TVM are supported by a grant of the University Hospitals Leuven (KOOR fonds and strategic projects). Kathleen Albert and Vital Noppen are thanked for their help with the acquisition of images of fetoscopic instruments. 


\section{References}

1. Westin B (1954) Hysteroscopy in early pregnancy. Lancet $11: 872$

2. Rodeck CH, Campbell S (1978) Early prenatal diagnosis of neural-tube defects by ultrasound-guided fetoscopy. Lancet 1 (8074):1128-1129

3. Laurence KM et al (1975) Hirschsprung's disease associated with congenital heart malformation, broad big toes, and ulnar polydactyly in sibs: a case for fetoscopy. J Med Genet 12 (4):334-338

4. Elias S, Esterly NB (1981) Prenatal diagnosis of hereditary skin disorders. Clin Obstet Gynecol 24(4):1069-1087

5. Michaelsson G (1981) Prenatal diagnosis of skin disorders. Acta Derm Venereol Suppl (Stockh) 95:64-66

6. Golbus MS et al (1989) Fetal tissue sampling. The San Francisco experience with 190 pregnancies. West J Med 150 (4):423-430

7. Rodeck CH, Campbell S (1978) Sampling pure fetal blood by fetoscopy in second trimester of pregnancy. Br Med J 2 (6139):728-730

8. Rodeck $\mathrm{CH}$ et al (1984) The management of severe rhesus isoimmunization by fetoscopic intravascular transfusions. Am J Obstet Gynecol 150(6):769-774

9. International Fetoscopy Group (1984) The status of fetoscopy and fetal tissue sampling. The results of the first meeting of the International Fetoscopy Group. Prenat Diagn 4(1):79-81

10. Daffos F, Capella-Pavlovsky M, Forestier F (1985) Fetal blood sampling during pregnancy with use of a needle guided by ultrasound: a study of 606 consecutive cases. Am J Obstet Gynecol 153(6):655-660

11. Quintero RA et al (1993) Transabdominal thin-gauge embryofetoscopy: a technique for early prenatal diagnosis and its use in the diagnosis of a case of Meckel-Gruber syndrome. Am J Obstet Gynecol 168(5):1552-1557

12. Luks FI, Deprest JA (1993) Endoscopic fetal surgery: a new alternative? Eur J Obstet Gynecol Reprod Biol 52(1):1-3

13. van der Wildt B et al (1995) Absence of electrical uterine activity after endoscopic access for fetal surgery in the rhesus monkey. Eur J Obstet Gynecol Reprod Biol 58(2):213-214

14. Golombeck K et al (2006) Maternal morbidity after maternalfetal surgery. Am J Obstet Gynecol 194(3):834-839

15. Deprest J et al (2006) Fetoscopic surgery: encouraged by clinical experience and boosted by instrument innovation. Semin Fetal Neonatal Med 11(6):398-412

16. Deprest JA, Lerut TE, Vandenberghe K (1997) Operative fetoscopy: new perspective in fetal therapy? Prenat Diagn 17 (13): $1247-1260$

17. Luks FI (1995) 9b Fetal surgery. Baillière's Clin Obstet Gynaecol 9(3):571-577

18. Kohl T et al (2006) Percutaneous fetoscopic patch coverage of spina bifida aperta in the human-early clinical experience and potential. Fetal Diagn Ther 21(2):185-193

19. Bruner JP et al (2000) In utero repair of myelomeningocele: a comparison of endoscopy and hysterotomy. Fetal Diagn Ther 15 (2):83-88

20. Welsh A et al (2003) Fetal cystoscopy in the management of fetal obstructive uropathy: experience in a single European centre. Prenat Diagn 23(13):1033-1041

21. Quintero RA et al (1995) In-utero percutaneous cystoscopy in the management of fetal lower obstructive uropathy. Lancet 346 (8974):537-540

22. Soldado F et al (2009) Fetoscopic release of extremity amniotic bands with risk of amputation. J Pediatr Orthop 29 (3):290-293
23. Keswani SG et al (2003) In utero limb salvage: fetoscopic release of amniotic bands for threatened limb amputation. J Pediatr Surg 38(6):848-851

24. Quintero RA et al (1997) In utero lysis of amniotic bands. Ultrasound Obstet Gynecol 10(5):316-320

25. Kohl T et al (2007) Partial amniotic carbon dioxide insufflation (PACI) facilitates fetoscopic interventions in complicated monochorionic twin pregnancies. Surg Endosc 21(8):1428-1433

26. Van Schoubroeck D et al (2004) Fetoscopic surgery in triplet pregnancies: a multicenter case series. Am J Obstet Gynecol 191 (5):1529-1532

27. Yamamoto M, Ville Y (2005) Twin-to-twin transfusion syndrome: management options and outcomes. Clin Obstet Gynecol 48(4):973-980

28. Crombleholme TM et al (2007) A prospective, randomized, multicenter trial of amnioreduction vs selective fetoscopic laser photocoagulation for the treatment of severe twin-twin transfusion syndrome. Am J Obstet Gynecol 197(4):396.e1-396.e9

29. Chang J et al (2006) Port insertion and removal techniques to minimize premature rupture of the membranes in endoscopic fetal surgery. J Pediatr Surg 41(5):905-909

30. Quintero RA et al (2006) Surgical management of twin reversed arterial perfusion sequence. Am J Obstet Gynecol 194(4):982-991

31. Lewi L et al (2006) Pregnancy and infant outcome of 80 consecutive cord coagulations in complicated monochorionic multiple pregnancies. Am J Obstet Gynecol 194(3):782-789

32. Ville $Y$ et al (1994) Endoscopic laser coagulation of umbilical cord vessels in twin reversed arterial perfusion sequence. Ultrasound Obstet Gynecol 4(5):396-398

33. Nakata M, Chmait RH, Quintero RA (2004) Umbilical cord occlusion of the donor versus recipient fetus in twin-twin transfusion syndrome. Ultrasound Obstet Gynecol 23(5):446450

34. Young BK et al (2005) Combined sonographic and endoscopic umbilical cord occlusion in twin and triplet gestations. J Perinat Med 33(6):530-533

35. Harrison MR et al (2003) A randomized trial of fetal endoscopic tracheal occlusion for severe fetal congenital diaphragmatic hernia. N Engl J Med 349(20):1916-1924

36. Jani JC et al (2009) Severe diaphragmatic hernia treated by fetal endoscopic tracheal occlusion. Ultrasound Obstet Gynecol 34 (3):304-310

37. Deprest J et al (2008) Enrichment of collagen plugs with platelets and amniotic fluid cells increases cell proliferation in sealed iatrogenic membrane defects in the foetal rabbit model. (Author reply). Prenat Diagn 28(9):878-880

38. Peiro JL et al (2009) Therapeutic indications of fetoscopy: a 5year institutional experience. J Laparoendosc Adv Surg Tech A 19(2):229-236

39. Middeldorp JM et al (2008) Selective feticide in monoamniotic twin pregnancies by umbilical cord occlusion and transection. Fetal Diagn Ther 23(2):121-125

40. Bruner JP et al (1999) Fetal surgery for myelomeningocele and the incidence of shunt-dependent hydrocephalus. JAMA 282 (19):1819-1825

41. Evrard VA et al (1997) Amnioinfusion with Hartmann's solution: a safe distention medium for endoscopic fetal surgery in the ovine model. Fetal Diagn Ther 12(3):188-192

42. Skarsgard ED et al (1995) Fetal endoscopic ('Fetendo') surgery: the relationship between insufflating pressure and the fetoplacental circulation. J Pediatr Surg 30(8):1165-1168

43. Bruner JP et al (1999) Endoscopic coverage of fetal myelomeningocele in utero. Am J Obstet Gynecol 180(1 Pt 1):153-158

44. Luks FI et al (1994) Carbon dioxide pneumoamnios causes acidosis in fetal lamb. Fetal Diagn Ther 9(2):105-109 
45. Gratacos E et al (2001) Effects of amniodistention with carbon dioxide on fetal acid-base status during fetoscopic surgery in a sheep model. Surg Endosc 15(4):368-372

46. Saiki $Y$ et al (1997) Reducing the deleterious effects of intrauterine $\mathrm{CO} 2$ during fetoscopic surgery. J Surg Res 69 (1):51-54

47. De Buck F, Deprest J, Van de Velde M (2008) Anesthesia for fetal surgery. Curr Opin Anaesthesiol 21(3):293-297

48. Ville $Y$ et al (1997) Diagnostic embryoscopy and fetoscopy in the first trimester of pregnancy. Prenat Diagn 17(13):1237-1246

49. Philipp $T$ et al (2004) Abnormal embryonic development diagnosed embryoscopically in early intrauterine deaths after in vitro fertilization: a preliminary report of 23 cases. Fertil Steril 82(5):1337-1342

50. Ferro J et al (2003) Improved accuracy of hysteroembryoscopic biopsies for karyotyping early missed abortions. Fertil Steril 80 (5):1260-1264

51. Philipp T et al (2003) Embryoscopic and cytogenetic analysis of 233 missed abortions: factors involved in the pathogenesis of developmental defects of early failed pregnancies. Hum Reprod 18(8):1724-1732

52. Hill M (2009) UNSW Embryology. Available from: http:// embryology.med.unsw.edu.au/

53. Paschopoulos M et al (2006) Embryofetoscopy: a new "old" tool. Gynecol Surg 3(2):79-83

54. Philipp T et al (2004) Effects of triploidy on early human development. Prenat Diagn 24(4):276-281

55. Philipp T, Kalousek DK (2003) Morphology of the 45, X embryo: an embryoscopic study. Am J Med Genet A 120A (3):314-319

56. Lewi L et al (2008) The outcome of monochorionic diamniotic twin gestations in the era of invasive fetal therapy: a prospective cohort study. Am J Obstet Gynecol 199(5):514 e1-514 e8

57. Quintero RA et al (1999) Staging of twin-twin transfusion syndrome. J Perinatol 19(8 Pt 1):550-555

58. Huber A et al (2006) Stage-related outcome in twin-twin transfusion syndrome treated by fetoscopic laser coagulation. Obstet Gynecol 108(2):333-337

59. El Kateb A, Ville Y (2008) Update on twin-to-twin transfusion syndrome. Best Pract Res Clin Obstet Gynaecol 22(1):63-75

60. Senat MV et al (2004) Endoscopic laser surgery versus serial amnioreduction for severe twin-to-twin transfusion syndrome. $\mathrm{N}$ Engl J Med 351(2):136-144

61. Bower SJ et al (1995) Uterine artery blood flow response to correction of amniotic fluid volume. Am J Obstet Gynecol 173 (2):502-507

62. Robyr R et al (2006) Prevalence and management of late fetal complications following successful selective laser coagulation of chorionic plate anastomoses in twin-to-twin transfusion syndrome. Am J Obstet Gynecol 194(3):796-803

63. Lenclen $\mathrm{R}$ et al (2007) Neonatal outcome in preterm monochorionic twins with twin-to-twin transfusion syndrome after intrauterine treatment with amnioreduction or fetoscopic laser surgery: comparison with dichorionic twins. Am J Obstet Gynecol 196(5):450 e1-450 e7

64. Stirnemann JJ et al (2008) A definition of selectivity in laser coagulation of chorionic plate anastomoses in twin-to-twin transfusion syndrome and its relationship to perinatal outcome. Am J Obstet Gynecol 198(1):62 e1-62 e6

65. Lewi L et al (2006) Intertwin anastomoses in monochorionic placentas after fetoscopic laser coagulation for twin-to-twin transfusion syndrome: is there more than meets the eye? Am J Obstet Gynecol 194(3):790-795

66. Cavicchioni $\mathrm{O}$ et al (2006) Intrauterine fetal demise following laser treatment in twin-to-twin transfusion syndrome. BJOG 113 (5):590-594
67. Quintero RA et al. (2009) Trocar-assisted selective laser photocoagulation of communicating vessels: A technique for the laser treatment of patients with twin-twin transfusion syndrome with inaccessible anterior placentas. J Matern Fetal Neonatal Med. doi:10.3109/14767050903177177

68. Huber A et al (2008) Laser coagulation of placental anastomoses with a 30 degrees fetoscope in severe mid-trimester twin-twin transfusion syndrome with anterior placenta. Ultrasound Obstet Gynecol 31(4):412-416

69. Quintero RA et al (2001) Selective laser photocoagulation of communicating vessels in severe twin-twin transfusion syndrome in women with an anterior placenta. Obstet Gynecol 97(3):477-481

70. Middeldorp JM et al (2007) Laparoscopically guided uterine entry for fetoscopy in twin-to-twin transfusion syndrome with completely anterior placenta: a novel technique. Fetal Diagn Ther 22(6):409-415

71. Deprest JA et al (1998) Alternative technique for Nd: YAG laser coagulation in twin-to-twin transfusion syndrome with anterior placenta. Ultrasound Obstet Gynecol 11(5):347-352

72. Rossi AC, D'Addario V (2008) Laser therapy and serial amnioreduction as treatment for twin-twin transfusion syndrome: a metaanalysis and review of literature. Am J Obstet Gynecol 198(2):147-152

73. Rossi AC, D'Addario V (2009) Comparison of donor and recipient outcomes following laser therapy performed for twintwin transfusion syndrome: a meta-analysis and review of literature. Am J Perinatol 26(1):27-32

74. Roberts D et al (2008) Interventions for twin-twin transfusion syndrome: a Cochrane review. Ultrasound Obstet Gynecol 31 (6):701-711

75. Lopriore E et al (2009) Risk factors for neurodevelopment impairment in twin-twin transfusion syndrome treated with fetoscopic laser surgery. Obstet Gynecol 113(2 Pt 1):361-366

76. Ortibus E et al (2009) The pregnancy and long-term neurodevelopmental outcome of monochorionic diamniotic twin gestations: a multicenter prospective cohort study from the first trimester onward. Am J Obstet Gynecol 200(5):494 e1-494 e8

77. Herberg $U$ et al (2006) Long term cardiac follow up of severe twin to twin transfusion syndrome after intrauterine laser coagulation. Heart 92(1):95-100

78. Van Mieghem T et al (2009) Assessment of fetal cardiac function before and after therapy for twin-to-twin transfusion syndrome. Am J Obstet Gynecol 200(4):400 e1-400 e7

79. Lewi L et al (2006) Diagnosis and management of heterokaryotypic monochorionic twins. Am J Med Genet 140(3):272-275

80. Arias $\mathrm{F}$ et al (1998) Treatment of acardiac twinning. Obstet Gynecol 91(5 Pt 2):818-821

81. Russell Z, Quintero RA, Kontopoulos EV (2007) Intrauterine growth restriction in monochorionic twins. Semin Fetal Neonatal Med 12(6):439-449

82. Gratacos E et al (2004) Prevalence of neurological damage in monochorionic twins with selective intrauterine growth restriction and intermittent absent or reversed end-diastolic umbilical artery flow. Ultrasound Obstet Gynecol 24(2):159-163

83. Gratacos E et al (2007) A classification system for selective intrauterine growth restriction in monochorionic pregnancies according to umbilical artery Doppler flow in the smaller twin. Ultrasound Obstet Gynecol 30(1):28-34

84. Adegbite AL et al (2004) Neuromorbidity in preterm twins in relation to chorionicity and discordant birth weight. Am J Obstet Gynecol 190(1):156-163

85. Lewi L et al (2007) Placental sharing, birthweight discordance, and vascular anastomoses in monochorionic diamniotic twin placentas. Am J Obstet Gynecol 197(6):587 e1-587 e8

86. Quintero RA et al (2001) Selective photocoagulation of communicating vessels in the treatment of monochorionic 
twins with selective growth retardation. Am J Obstet Gynecol 185(3):689-696

87. O'Donoghue K et al (2009) Transfusional fetal complications after single intrauterine death in monochorionic multiple pregnancy are reduced but not prevented by vascular occlusion. BJOG 116(6):804-812

88. Robyr R, Yamamoto M, Ville Y (2005) Selective feticide in complicated monochorionic twin pregnancies using ultrasound-guided bipolar cord coagulation. BJOG 112 (10):1344-1348

89. Lee $\mathrm{H}$ et al (2007) Efficacy of radiofrequency ablation for twinreversed arterial perfusion sequence. Am J Obstet Gynecol 196 (5):459 e1-459 e4

90. Moise KJ Jr et al (2008) Radiofrequency ablation for selective reduction in the complicated monochorionic gestation. Am J Obstet Gynecol 198(2):198 e1-198 e5

91. Sepulveda W, Sebire NJ (2004) Acardiac twin: too many invasive treatment options-the problem and not the solution. Ultrasound Obstet Gynecol 24(4):387-389

92. Hecher $\mathrm{K}$ et al (2006) Twin reversed arterial perfusion: fetoscopic laser coagulation of placental anastomoses or the umbilical cord. Ultrasound Obstet Gynecol 28(5):688-691

93. Hedrick HL et al (2007) Liver position and lung-to-head ratio for prediction of extracorporeal membrane oxygenation and survival in isolated left congenital diaphragmatic hernia. Am J Obstet Gynecol 197(4):422 e1-422 e4

94. Jani J et al (2006) Prenatal prediction of survival in isolated leftsided diaphragmatic hernia. Ultrasound Obstet Gynecol 27 (1): $18-22$

95. Jani $J$ et al (2007) Observed to expected lung area to head circumference ratio in the prediction of survival in fetuses with isolated diaphragmatic hernia. Ultrasound Obstet Gynecol 30 (1):67-71

96. Deprest J, Gratacos E, Nicolaides KH (2004) Fetoscopic tracheal occlusion (FETO) for severe congenital diaphragmatic hernia: evolution of a technique and preliminary results. Ultrasound Obstet Gynecol 24(2):121-126

97. Flageole $\mathrm{H}$ et al (1998) The plug-unplug sequence: an important step to achieve type II pneumocyte maturation in the fetal lamb model. J Pediatr Surg 33(2):299-303

98. Thomas Kohl UG, Tchatcheva K, Schaible T (2006) Deliberately delayed and shortened fetoscopic tracheal occlusion-a different strategy after prenatal diagnosis of life-threatening congenital diaphragmatic hernias (letter). J Pediatr Surg 41 (7):1344-1345

99. Jan Deprest JJ, Gratacos E, Nicolaides K (2006) Deliberately delayed and shortened fetoscopic tracheal occlusion: a different strategy after prentatal diagnosis of life-threatening congenital diaphragmatic hernias (Letter, reply). J Pediatr Surg 41(7):1345-1346

100. Mieke Cannie JJ, de Keyzer F, Doné E, van Mieghem T, Guccardio L, Dymarkowski S, Deprest J (2007) Lung response to fetal tracheal occlusion is better prior to 29 weeks than after. Am J Obstet Gynecol 197(6):S161

101. Kohl T et al (2009) Life-saving effects of fetal tracheal occlusion on pulmonary hypoplasia from preterm premature rupture of membranes. Obstet Gynecol 113(2 Pt 2):480-483

102. Mirzai $\mathrm{H}$ et al (1998) Outcome of patients with meningomyelocele: the Ege University experience. Childs Nerv Syst 14 (3):120-123

103. Bowman RM et al (2001) Spina bifida outcome: a 25-year prospective. Pediatr Neurosurg 34(3):114-120

104. Steinbok P et al (1992) Long-term outcome and complications of children born with meningomyelocele. Childs Nerv Syst 8 (2):92-96
105. Johnson MP et al (2003) Fetal myelomeningocele repair: short-term clinical outcomes. Am J Obstet Gynecol 189 (2):482-487

106. Brunelli G, Brunelli F (1984) Experimental foetal microsurgery as related to myelomeningocele. Microsurgery 5(1):24-29

107. Kohl T et al (2009) Percutaneous fetoscopic patch closure of human spina bifida aperta: advances in fetal surgical techniques may obviate the need for early postnatal neurosurgical intervention. Surg Endosc 23(4):890-895

108. Fichter MA et al (2008) Fetal spina bifida repair-current trends and prospects of intrauterine neurosurgery. Fetal Diagn Ther 23 (4):271-286

109. Mazzola CA et al (2002) Dermoid inclusion cysts and early spinal cord tethering after fetal surgery for myelomeningocele. $\mathrm{N}$ Engl J Med 347(4):256-259

110. Aaronson OS et al (2002) Robot-assisted endoscopic intrauterine myelomeningocele repair: a feasibility study. Pediatr Neurosurg 36(2):85-89

111. Pilu G et al (2002) Diagnosis of Fetal Abnormalities - The 18 23 weeks scan. ISUOG \& Fetal Medicine Foundation, London

112. Benachi A et al (2006) Prenatally diagnosed sacrococcygeal teratoma: a prognostic classification. J Pediatr Surg 41 (9): $1517-1521$

113. Bond SJ et al (1990) Death due to high-output cardiac failure in fetal sacrococcygeal teratoma. J Pediatr Surg 25(12):12871291

114. Westerburg B et al (2000) Sonographic prognostic factors in fetuses with sacrococcygeal teratoma. J Pediatr Surg 35(2):322325, discussion 325-6

115. Makin EC et al (2006) Outcome of antenatally diagnosed sacrococcygeal teratomas: single-center experience (19932004). J Pediatr Surg 41(2):388-393

116. Adzick NS et al (1997) A rapidly growing fetal teratoma. Lancet 349(9051):538

117. Graf JL et al (2000) Successful fetal sacrococcygeal teratoma resection in a hydropic fetus. J Pediatr Surg 35(10):1489-1491

118. Hedrick HL et al (2004) Sacrococcygeal teratoma: prenatal assessment, fetal intervention, and outcome. J Pediatr Surg 39 (3):430-438, discussion 430-8

119. Lam YH, Tang MH, Shek TW (2002) Thermocoagulation of fetal sacrococcygeal teratoma. Prenat Diagn 22(2):99-101

120. Paek BW et al (2001) Radiofrequency ablation of human fetal sacrococcygeal teratoma. Am J Obstet Gynecol 184(3):503-507

121. Ruano R, Duarte S, Zugaib M (2009) Percutaneous Laser Ablation of Sacrococcygeal Teratoma in a Hydropic Fetus with Severe Heart Failure - Too Late for a Surgical Procedure? Fetal Diagn Ther 25(1):26-30

122. Hecher K, Hackeloer BJ (1996) Intrauterine endoscopic laser surgery for fetal sacrococcygeal teratoma. Lancet 347 (8999):470

123. Quarello E et al (2005) Prenatal laser treatment of a placental chorioangioma. Ultrasound Obstet Gynecol 25(3):299-301

124. Quintero RA et al (1996) In utero endoscopic devascularization of a large chorioangioma. Ultrasound Obstet Gynecol 8 (1):48-52

125. Sepulveda W et al (2009) Endoscopic laser coagulation of feeding vessels in large placental chorioangiomas: report of three cases and review of invasive treatment options. Prenat Diagn 29 (3):201-206

126. Lau TK et al (2003) Prenatal treatment of chorioangioma by microcoil embolisation. BJOG 110(1):70-73

127. Nicolini U et al (1999) Alcohol injection: a new method of treating placental chorioangiomas. Lancet 353(9165):1674-1675

128. McLorie $G$ et al (2001) Outcome analysis of vesicoamniotic shunting in a comprehensive population. J Urol 166(3):1036-1040 
129. Wilson RD, Johnson MP (2003) Prenatal ultrasound guided percutaneous shunts for obstructive uropathy and thoracic disease. Semin Pediatr Surg 12(3):182-189

130. Won HS et al (2006) Vesicoamniotic shunting using a doublebasket catheter appears effective in treating fetal bladder outlet obstruction. Acta Obstet Gynecol Scand 85(7):879-884

131. Elder JS, Duckett JW Jr, Snyder HM (1987) Intervention for fetal obstructive uropathy: has it been effective? Lancet 2 (8566):1007-1010
132. Quintero RA et al (1995) Percutaneous fetal cystoscopy and endoscopic fulguration of posterior urethral valves. Am J Obstet Gynecol 172(1 Pt 1):206-209

133. Quintero RA et al (2000) Successful in utero endoscopic ablation of posterior urethral valves: a new dimension in fetal urology. Urology 55(5):774

134. Quintero RA et al (2000) Fetal hydrolaparoscopy and endoscopic cystotomy in complicated cases of lower urinary tract obstruction. Am J Obstet Gynecol 183(2):324-330, discussion 330-3 